\title{
USA PRACTITIONERS' PERCEPTION OF BIM MATURITY
}

\author{
Dylan John ${ }^{1}$, Yunfeng Chen ${ }^{2}$, Robert F. Cox ${ }^{3}$, and Qian Huang ${ }^{4}$
}

\begin{abstract}
This paper examines the USA practitioner's perspective of Building Information Modeling Maturity (BIMM). The objective is to better identify the BIMM indicators from practitioners' perspective as it would provide better insight and feedback into the use and practice of BIM in the USA industry. This would help fill the gap in understanding and breaking down the complexity of BIM and will allow for better approaches to BIM education and more tangible adoption in Industry.

The study is structured based off the four BIMM factors of Technology, Information, Process and People. A survey was used as the research methodology with a breakdown of the survey responses based on their business type and number of years working with BIM. The research findings indicate that Information is the most important maturity factor, followed by Process and the lowest ranked maturity factor is People followed by Technology. The findings of this study has both academic and industry value as it gives greater insight to the practitioners perspective of the different maturity indicators and as such can be used to develop better BIM education and industry adoption practices.
\end{abstract}

Keywords: BIM, maturity, USA, practitioner.

\section{INTRODUCTION}

Building Information Modeling Maturity (BIMM) is still evolving as researchers and industry professionals try to identify the best possible means of pin pointing how we can accurately assess and understand the maturity level of Building Information Modeling (BIM) (Chen et al. 2014). BIMM is defined as the "extent to which BIM is explicitly defined, managed, integrated and optimized" (Succar 2010). Many practitioners accept established standards such as the National BIM Standard, but literature review indicates that there are efforts to better define a format that can be widely accepted and cover what BIM entails. Chen, identified in her study of BIMM, factors such as Information, Process and Technology management (Chen et al. 2016) and yet other studies have highlighted technology and process but also introduced the policy factor (Succar et al. 2012).

The need for identifying BIM maturity factors extend beyond industry practice to educational environments that prepare professionals for BIM related tasks. Sacks attempts to identify the needs of a structured and more organized BIM education to bridge the gap between the preparations in academic institutions as it would translate to the needs of industry (Sacks and Pikas 2013). Studies by Sacks have revealed 37 subject topics

1 Graduate Student, Department of Civil Engineering and Construction Management, Georgia Southern University, Statesboro, USA, david d john@georgiasouthern.edu

2 Assistant Professor, Department of Civil Engineering and Construction Management, Georgia Southern University, Statesboro, USA, ychen@georgiasouthern.,edu

3 Associate Dean of Globalization, Professor of School of CMT, Purdue University, West Lafayette, IN, USA, 47907, PH (1) 7654042244, Email: rfcox@purdue.edu

4 Assistant Professor, School of Architecture, Southern Illinois University Carbondale, Carbondale, IL, USA, 62901, PH (1) 6184531254, Email: qhuang@siu.edu 
categorized under process, technology and applications that need to be incorporated to ensure an effective BIM education. Studies done by (Sacks et al. 2010) also identified that there was a lack of experience for those who teach BIM in these institutions. This study which aims to better understand the practitioners perspective of BIM, would allow for educators to better focus on how and where to improve their BIM education courses.

While many of the above studies have been done to either identify a measurement model for the maturity of BIM or the methods and means of structuring education to meet the needs and demands of the industry, this paper will attempt to identify the most important indicators of BIMM by studying data collected through research about the USA Practitioners perspective of BIMM. A better and deeper understanding of the practitioner's perspective will give greater insight into BIMM and improve both the industry and educational approaches to BIM.

\section{LITERATURE REVIEW}

BIM is growing rapidly and this growth has highlighted the need for the development of guides to BIM implementation. One such resource is the National BIM Standard, Capability Maturity Model (CMM), which is a preliminary BIMM assessment model structured off information management. A new version of CMM is known as Interactive Capability Maturity Model (I-CMM), which evolved by identifying a need-based challenge to keep the model accurate and updated (Morlhon et al. 2014). While CMM and I-CMM are accepted by industry professionals as maturity assessment models, they lack definitions in relation to the comprehensive nature of BIM.

Research has been done at the global stage to assess BIM and how it is being adopted. Gerges studied the practitioner's perspective of BIM implementation in Kuwait (Gerges et al. 2016). Jensen and Johanneson compared important elements of BIM implementation between Denmark and Iceland (Jensen and Johanneson 2013). Many studies on BIM outside of the US, have lacked the comprehensive approach of identifying BIMM factors beyond the Information Communication Technology realm. These studies take a look at the implementation of BIM but do not seem to identify and explore maturity factors such as process management, people and policy.

In recent years, literature related to BIMM has indicated more empirical approaches to assess BIMM. These studies reveal that at the core of BIMM, there is information management. These studies also highlight the need to consider both process and technology (Chen et al. 2016). Some studies on BIM implementation and its maturity levels around the world indicate that there is a need for active participation by stakeholders who influence and manage projects to ensure proper and productive implementation of BIM (Wong et al. 2010). Three factors of technology, process, and people are included in a road map to effective implementation of BIM (Khosrowshahi and Arayici 2016). Succar, highlights three interlocking fields for BIM activity namely: technology, process and policy (Succar et al. 2012). This indicates that multiple studies have identified the validity and importance of these areas in BIMM. This clearly establishes the importance of these factors which are used as a basis of this study. A comprehensive list of 27 BIMM indicator and their underlying factors were listed in Table 1 . This study will aim to identify the USA practitioner's perspective of BIM on the maturity indicators that have been grouped under these specific factors. 
Table 1: BIMM Dimensions and Indicators (Chen 2013)

\begin{tabular}{cc}
\hline BIMM Dimensions & BIMM Indicators \\
\hline $\begin{array}{c}\text { Technology (Chen 2013); (Succar } \\
\text { 2010); (Jung and Joo 2011) }\end{array}$ & Software; Interoperability; Hardware Equipment; Hardware \\
Upgrade (HU) & Information Delivery Method (IDM); Information Assurance \\
Information (Chen et al. 2014); & (IAS); Data Richness; Real-Time Data (RTD); Information \\
(Computer Integrated Construction & Accuracy (IAC); Graphics; Geospatial Capability (GeoC); Work \\
2011); (National Institute of Building & Flow; Documentation and Modeling Standards (DMS) \\
Science 2007) & Process \& Tech Innovation (PTI); Strategic Planning (SP); \\
Process (Giel and Issa 2013); (Gu and & Lifecycle Process; Change Management (CHM); Risk \\
London 2010);(Mom et al. & Management; Standard Operating Process (SOP); Quality \\
2011);(Succar 2010) & Control; Specification \\
People (Chen 2013); (Computer & Senior Leadership (SL); Role; Reward System; Competency \\
Integrated Construction 2013);(Gu & Profile (CP); Training Program (TP); Training Delivery Method \\
and London 2010); (Gu et al. 2014) & (TDM) \\
\hline
\end{tabular}

\section{METHODOLOGY}

The USA practitioner's perspective of BIMM indicators are assessed from data collected from an online survey. The analysis included a demographic analysis and an analysis of the mean ranking on a 7 point Likert scale for BIMM indicators (Chen et al. 2016). The demographic analysis identified elements such as business type and project experience. A statistical analysis was then performed to identify the mean and standard deviations (SD) of the data. The higher mean indicates great importance.

\section{DATA COLlection}

The survey was taken by 75 respondents who represented multiple disciplines including Owner/Developer (O/D), Architect/Engineer (A/E), General Contractor (GC)/ Construction Manager (CM), Subcontractor, Consultant and Software Vendors (SV). The survey consisted of four parts of organization information, personal information, evaluation of BIMM and a section for free response/comments.

\section{DATA ANALYSIS}

\subsection{Demographic Information}

The sample of respondents included $28 \% \mathrm{GC}, 25 \% \mathrm{~A} / \mathrm{E}, 16 \%$ consultant, $7 \%$ sub contractors, $8 \% \mathrm{O} / \mathrm{D}$, and $8 \% \mathrm{SV}$ respectively. Additionally, $40 \%$ of respondents had over 8 years of BIM-related experience with a total of $83 \%$ of the respondents having over three years of BIM-related experience. 17\% had been working on BIM projects in the industry for less than three years. This indicates that the responders have significant BIM-related experience and therefore can be considered as BIM experts.

\subsection{Comparison of Indicator Mean and Ranking}

Descriptive statistics were used to identify the Mean, SD and Ranking of each of the indicators. The closer is the mean for different groups (the smaller the mean difference is), the greater are the reliability and consistency between practitioner perceptions, of the 
BIMM indicators importance. Additionally, the highlighted rankings of these indicators, serve as a listing of the most to least important BIMM indicators.

\subsubsection{Business Type}

Survey responses were collected from different business types including $O / D, A / E$, GC/CM, Subcontractors, Consultants, SV and others. Some business types that were combined together for the purpose of analysis with the premise that they hold similar perspectives in relation to the use of BIM, and their roles and responsibility in a project. Table 2 provides the mean, SD and rank of each of the identified 27 BIMM indicators.

Technology: Interoperability ranked relatively high and in most instances within the Top 5. Applications were mostly valued by A/E and Consultants, while many of the other business types ranked it at 10 or below. Hardware equipment and hardware upgrade were ranked relatively low and in some instances were at the lowest of BIMM indicators.

Information: Information delivery and information assurance were ranked in the Top 10. Data richness and Real time data as indicators were of greater value and importance to $(\mathrm{O} / \mathrm{D})$ and $(\mathrm{A} / \mathrm{E})$, with Data richness ranking very high for software vendors. Information accuracy clinched the number one rank in every business type except for $\mathrm{GC} / \mathrm{CM}$ and consultants. This clearly indicates that the information component of BIM is a very critical indicator. Graphics ranked relatively low.

Process: For process, indicators such as quality control and specifications seem to have the most number of indicators as expressed by business types in the top 10 maturity indicators. Quality control ranked in the top 10 in almost all business types except for O/D. Both O/D and Subcontractors identified SOP to be an important indicator of BIMM.

People: The people component is very interesting as it has a very vast contrast of ranking among its indicators. Almost all business types indicated senior leadership as a very important indicator within the top 10 BIMM indicators. On the opposite side of the spectrum, reward systems is not highly favoured and seems to rank extremely low. Training programs are considered significant and important by many of the business types except for $(\mathrm{O} / \mathrm{D})$, Subcontractors and Consultants.

It is clear that information stands out as one of the key factors/areas that businesses focus in identifying the key maturity indicators of BIM. The BIMM indicators with minimum mean are identified to be Training Delivery Method (O/D), Reward System for both (A/E), (Consultant) and(Subcontractor) and Hardware upgrade (SV).

\subsubsection{BIM-related Experience - Number of Years}

This section of the data analysis evaluated the respondents experience by number of years in the industry and having worked with BIM. Table 3 lists the mean scores, standard deviation, and ranking of each BIMM indicators, as well as the biggest rank difference.

Technology: Interoperability seemed to be an important maturity indicator for most practitioners. Applications also ranked within the top 10 to most categories in experience years, except the $3-5$ year experience category which seemed to give it a lower rank at about 16 out of the 27 identified indicators. Hardware equipment and hardware upgrade were significantly lower on being identified as an important indicator.

Information: IDM and IAS both ranked consistently at all experience levels within the top 10 indicators of BIMM. IAC also consistently ranked high with all experience categories having listed it in not just the top 10 indicators but event ranking it as high as in the top five indicators of BIMM. DMS was found to be listed on most of the categories and graphics as in the business type analysis was of significantly less importance. 
Table 2: Mean of perceived importance of BIMM indicators (business type)

\begin{tabular}{|c|c|c|c|c|c|c|c|}
\hline BIMM Indicators & $\mathrm{O} / \mathrm{D}(\mathrm{N}=6)$ & $\mathrm{A} / \mathrm{E}(\mathrm{N}=31)$ & $\mathrm{GC} / \mathrm{CM}(\mathrm{N}=24)$ & $\begin{array}{l}\text { Subcontractor } \\
\qquad(\mathrm{N}=5)\end{array}$ & $\begin{array}{l}\text { Consultant } \\
\qquad(\mathrm{N}=18)\end{array}$ & $\mathrm{SV}(\mathrm{N}=18)$ & $\begin{array}{c}\text { Biggest } \\
\text { Rank } \\
\text { Difference }\end{array}$ \\
\hline Software & $5.83(0.75,18)$ & $6.21(1.18,2)$ & $5.86(0.79,10)$ & $5.80(1.10,20)$ & $6.33(0.65,5)$ & $6.17(0.75,12)$ & 18 \\
\hline Interoperability & $6.33(0.52,4)$ & $5.84(1.21,13)$ & $6.29(0.64,1)$ & $6.60(0.55,2)$ & $6.67(0.49,1)$ & $6.17(1.17,13)$ & 12 \\
\hline Hardware & $5.50(0.84,21)$ & $5.68(1.29,14)$ & $5.81(0.93,15)$ & $5.40(1.14,23)$ & $5.58(0.51,20)$ & $4.83(2.04,26)$ & 12 \\
\hline $\mathrm{HU}$ & $5.50(0.84,22)$ & $5.58(1.12,16)$ & $5.48(1.12,24)$ & $5.00(1.41,26)$ & $5.25(0.75,25)$ & $4.83(2.04,26)$ & 11 \\
\hline IDM & $6.00(0.63,13)$ & $6.16(1.21,3)$ & $5.86(0.79,10)$ & $6.60(0.55,2)$ & $6.42(0.67,2)$ & $6.50(1.22,6)$ & 11 \\
\hline IAS & $6.67(0.52,3)$ & $5.95(1.18,8)$ & $5.86(0.65,9)$ & $6.40(0.55,4)$ & $6.42(0.67,2)$ & $6.67(0.52,2)$ & 7 \\
\hline PTI & $5.83(0.75,18)$ & $5.47(1.47,20)$ & $5.81(0.81,14)$ & $5.80(0.84,17)$ & $5.75(0.75,14)$ & $5.83(0.98,21)$ & 7 \\
\hline SP & $6.33(0.82,5)$ & $5.84(0.83,12)$ & $6.10(0.70,5)$ & $6.20(0.84,8)$ & $5.83(0.72,13)$ & $6.17(1.33,15)$ & 10 \\
\hline SL & $6.83(0.41,1)$ & $6.00(1.41,7)$ & $6.29(0.64,1)$ & $6.40(0.89,5)$ & $6.42(0.67,2)$ & $6.50(0.84,5)$ & 6 \\
\hline Data Richness & $6.17(0.89,12)$ & $5.89(0.99,10)$ & $5.81(0.75,13)$ & $6.00(1.00,13)$ & $5.58(1.00,22)$ & $5.67(0.52,2)$ & 20 \\
\hline RTD & $6.00(0.89,14)$ & $5.53(1.17,18)$ & $5.76(1.04,18)$ & $5.80(0.45,16)$ & $5.50(1.00,23)$ & $5.67(1.03,24)$ & 10 \\
\hline IAC & $6.83(0.41,1)$ & $6.26(1.24,1)$ & $6.29(0.72,3)$ & $6.80(0.45,1)$ & $6.08(0.90,6)$ & $7.00(0.00,1)$ & 5 \\
\hline Graphics & $5.50(0.84,22)$ & $5.26(1.41,24)$ & $5.48(0.87,23)$ & $5.60(0.55,21)$ & $5.58(0.79,21)$ & $5.83(0.75,20)$ & 4 \\
\hline GeoC & $5.50(1.38,26)$ & $5.53(1.31,19)$ & $5.71(1.19,20)$ & $5.40(1.14,23)$ & $5.67(1.07,19)$ & $5.17(1.47,25)$ & 7 \\
\hline Lifecycle Process & $6.33(0.82,5)$ & $5.00(1.41,26)$ & $5.38(1.36,25)$ & $6.00(0.71,10)$ & $5.67(0.78,16)$ & $5.83(2.40,22)$ & 21 \\
\hline Work Flow & $6.17(0.75,8)$ & $5.63(1.01,15)$ & $5.52(1.17,22)$ & $6.20(0.45,7)$ & $6.00(0.74,9)$ & $6.33(0.82,8)$ & 15 \\
\hline $\mathrm{CHM}$ & $6.17(0.75,8)$ & $5.89(1.20,11)$ & $5.81(1.08,16)$ & $6.40(0.89,5)$ & $5.67(0.78,16)$ & $6.17(1.17,13)$ & 11 \\
\hline Role & $6.33(0.82,5)$ & $5.33(0.84,22)$ & $5.90(1.04,8)$ & $5.40(1.14,23)$ & $5.75(0.75,14)$ & $6.40(0.89,7)$ & 15 \\
\hline Reward System & $5.67(0.82,20)$ & $4.33(1.24,27)$ & $4.52(1.33,27)$ & $6.00(0.71,10)$ & $5.00(0.74,27)$ & $6.00(1.00,17)$ & 10 \\
\hline Risk Management & $5.50(0.84,22)$ & $5.28(0.89,23)$ & $5.71(1.27,21)$ & $6.00(1.00,13)$ & $5.92(0.79,11)$ & $6.00(0.71,16)$ & 12 \\
\hline SOP & $5.67(1.21,22)$ & $5.56(1.04,17)$ & $5.86(0.91,12)$ & $5.20(0.84,25)$ & $6.08(0.90,6)$ & $6.20(0.84,9)$ & 19 \\
\hline DMS & $6.33(0.82,5)$ & $6.11(0.90,5)$ & $6.00(0.89,7)$ & $5.80(0.84,17)$ & $6.08(0.90,6)$ & $6.60(0.89,4)$ & 13 \\
\hline Quality Control & $6.00(1.10,17)$ & $6.00(0.69,6)$ & $6.14(0.65,4)$ & $6.00(0.71,10)$ & $6.00(0.74,9)$ & $6.20(0.84,9)$ & 13 \\
\hline Specifications & $6.17(0.75,8)$ & $5.39(0.98,21)$ & $5.19(1.47,26)$ & $6.20(1.10,9)$ & $5.92(0.79,11)$ & $6.00(1.00,17)$ & 17 \\
\hline $\mathrm{CP}$ & $6.00(0.89,14)$ & $5.89(0.83,9)$ & $5.81(1.08,17)$ & $6.00(0.71,10)$ & $5.25(0.97,26)$ & $6.00(1.00,17)$ & 17 \\
\hline Training Program & $6.00(0.89,14)$ & $6.11(0.76,4)$ & $6.05(1.02,6)$ & $6.00(1.00,13)$ & $5.67(0.89,18)$ & $6.20(0.84,9)$ & 14 \\
\hline TDM & $5.33(1.03,27)$ & $5.17(0.99,25)$ & $5.71(0.90,19)$ & $5.80(0.84,17)$ & $5.42(1.00,24)$ & $5.80(1.30,23)$ & 10 \\
\hline
\end{tabular}

Process: It was interesting to observe that strategic planning was of greater importance to those of greater experience in years while change management was a more important indicator of BIMM to those who had lesser experience in years. Quality control is another indicator under process which ranked consistently within the top 10 indicators.

People: Senior leadership was an indicator that was highlighted as a BIMM indicator among all categories as it ranked within the top ten. Other indicators while not as significant included competency profile and training programs. 
Table 3: Mean of perceived importance of BIMM indicators (years of experience)

\begin{tabular}{|c|c|c|c|c|c|}
\hline BIMM Indicators & $\begin{array}{c}1 \leq \text { Year }<3 \\
(\mathrm{~N}=13)\end{array}$ & $\begin{array}{c}3 \leq \text { Year }<5 \\
(\mathrm{~N}=21)\end{array}$ & $\begin{array}{c}5 \leq \text { Year }<8 \\
(\mathrm{~N}=11)\end{array}$ & $\begin{array}{l}8 \leq Y e a r \\
(N=30)\end{array}$ & $\begin{array}{c}\text { Biggest Rank } \\
\text { Difference }\end{array}$ \\
\hline Software & $6.31(0.63,5)$ & $5.86(0.85,16)$ & $6.18(0.60,5)$ & $5.87(1.31,10)$ & 11 \\
\hline Interoperability & $6.62(0.65,1)$ & $6.29(0.64,3)$ & $6.27(0.65,3)$ & $6.10(1.09,4)$ & 3 \\
\hline Hardware & $5.77(0.83,19)$ & $5.76(0.70,17)$ & $5.82(0.98,13)$ & $5.37(1.38,25)$ & 12 \\
\hline $\mathrm{HU}$ & $5.54(0.78,23)$ & $5.62(0.80,21)$ & $5.45(1.04,21)$ & $5.20(1.45,26)$ & 5 \\
\hline IDM & $6.54(0.66,2)$ & $6.14(0.91,9)$ & $6.36(0.50,1)$ & $6.03(1.13,7)$ & 8 \\
\hline IAS & $6.31(063,5)$ & $6.14(0.79,7)$ & $6.36(0.67,2)$ & $6.10(1.03,3)$ & 5 \\
\hline PTI & $5.92(0.64,13)$ & $5.95(0.67,11)$ & $5.82(0.87,11)$ & $5.40(1.28,24)$ & 13 \\
\hline SP & $5.92(0.95,14)$ & $6.24(0.70,5)$ & $6.00(0.89,8)$ & $5.87(0.86,9)$ & 9 \\
\hline SL & $6.08(0.95,9)$ & $6.33(0.86,2)$ & $6.00(1.18,9)$ & $6.43(1.07,1)$ & 8 \\
\hline Data Richness & $6.08(0.64,8)$ & $5.95(0.86,13)$ & $5.55(0.93,19)$ & $5.93(0.98,8)$ & 11 \\
\hline RTD & $5.77(0.73,18)$ & $5.62(0.97,22)$ & $5.18(1.17,25)$ & $5.73(1.01,17)$ & 8 \\
\hline IAC & $6.54(0.66,2)$ & $6.52(0.81,1)$ & $6.27(0.79,4)$ & $6.33(1.03,2)$ & 2 \\
\hline Graphics & $5.38(1.45,25)$ & $5.43(0.60,24)$ & $5.73(1.10,15)$ & $5.43(0.94,23)$ & 10 \\
\hline GeoC & $6.00(0.91,10)$ & $5.33(1.11,25)$ & $5.00(1.41,26)$ & $5.77(1.17,16)$ & 16 \\
\hline Lifecycle Process & $5.69(0.95,21)$ & $5.33(1.28,26)$ & $5.45(1.13,22)$ & $5.60(1.59,20)$ & 6 \\
\hline Work Flow & $6.00(0.91,10)$ & $5.76(0.89,18)$ & $5.64(1.03,18)$ & $5.83(0.99,12)$ & 8 \\
\hline CHM & $6.15(0.80,7)$ & $6.05(0.74,10)$ & $5.82(0.87,11)$ & $5.80(1.24,14)$ & 7 \\
\hline Role & $5.69(1.11,22)$ & $5.71(0.85,20)$ & $5.73(1.10,15)$ & $5.79(0.92,15)$ & 7 \\
\hline Reward System & $4.46(1.05,27)$ & $5.00(0.84,27)$ & $4.45(1.69,27)$ & $4.71(1.38,27)$ & 0 \\
\hline Risk Management & $5.69(0.75,20)$ & $5.52(0.93,23)$ & $5.73(0.90,14)$ & $5.68(1.22,18)$ & 9 \\
\hline SOP & $5.92(0.95,14)$ & $5.90(1.09,15)$ & $5.55(1.04,20)$ & $5.64(0.95,19)$ & 6 \\
\hline DMS & $6.38(0.65,4)$ & $6.29(1.06,4)$ & $5.91(0.94,10)$ & $5.86(0.85,11)$ & 7 \\
\hline Quality Control & $6.00(0.91,10)$ & $6.19(0.75,6)$ & $6.18(0.60,5)$ & $6.04(0.64,6)$ & 5 \\
\hline Specifications & $5.92(0.95,14)$ & $5.76(1.00,19)$ & $5.27(1.42,23)$ & $5.54(1.17,22)$ & 9 \\
\hline $\mathrm{CP}$ & $5.38(0.96,24)$ & $5.95(0.67,11)$ & $6.00(0.77,7)$ & $5.82(1.16,13)$ & 13 \\
\hline Training Program & $5.85(0.80,17)$ & $6.14(0.85,8)$ & $5.73(1.10,15)$ & $6.07(0.81,5)$ & 12 \\
\hline TDM & $5.00(0.71,26)$ & $5.90(0.83,14)$ & $5.27(1.49,24)$ & $5.54(0.96,21)$ & 12 \\
\hline
\end{tabular}

The USA practitioners with different levels of experience by years seem to place significant importance on Information, with specific attention to IDM and IAS. This is very similar to the results of the analysis on practitioners from different business types.

\section{DELIMitATIONS AND LimitATIONS}

Some limitations of this study need to be acknowledged. First, this study is delimited to the perspective of practitioners in the USA. A previous study of global practitioners' perception of BIMM indicators was conducted and published in 2016 (Chen et al. 2016). 
Although both studies identified information factor as the most important factor regardless of different categorizations, there are difference between the two studies in the top four indicators and the ranking of some indicators and factors. In addition, the demographics of the practitioner's perspective are limited to two professional role based demographic categories. These categories included business type, and experience based on number of years in industry. This also may be considered as a potential area for future study with the analysis of other demographics such as positions, number of BIM-related projects, location, and gender. The final limitation as identified by this study is the comparison of practitioner perspectives being based on singular groupings and not combinations. For example, a comparison of the practitioner's perspective if business type and experience factors were combined and studied for additional perspective.

\section{CONCLUSIONS}

This study examines the importance of each individual BIMM indicator as per the responses from BIM related practitioners grouped based on their business type and experience. The key findings of the study are summarized below in relation to the BIMM indicator, the dimension under which it was grouped and its ranking difference.

First, the study highlights that the top four indicators as assessed from the USA practitioner's perspective is Information Accuracy, Interoperability, Info Assurance and Info Delivery Method. The least valued indicators for BIMM seemed to be reward systems and graphics. This further emphasizes that practitioners value BIM for its capabilities beyond just the realm of graphics and visualization and have begun to embrace the aspects of collaboration, knowledge and information sharing a lot more. Another indicator that ranked low was hardware upgrades. With the existing usage of hardware, this may not have been seen as a necessity and therefore not valued as much.

Second, it is clearly observed that information is one of the most critical dimension of BIMM when assessed in the USA practitioner's perspective and is followed by the process dimension. The study also indicates that the lowest ranking dimension is people followed by technology. Again, this may be as a result of technology already being adopted and therefore not seen as a significant dimension by practitioners who have begun to understand and value the more collaborative and information based aspects of BIM.

This study provides both theoretical and practical insight into BIMM. Theoretically the study has empirical evidence to justify the USA practitioner's perspective on the different indicators and dimensions of BIM. The findings will aid with future study by academia and also contribute towards focused BIM education based on the selected professional career tracks. The findings can also be used to create a more comprehensive understanding of the independent professional role based expectations of BIM, and will help alleviate misunderstandings and misconceptions related to BIM. On a more practical level, the findings of this study can be used in a broader understanding of what areas require more focus to help with BIMM within a company in the context of the USA.

\section{REFERENCES}

Chen, Y. (2013). Measurement Models of Building Information Modeling, unpublished thesis Purdue University.

Chen, Y., Dib, H. and Cox, R. F. (2014). A measurement model of building information modelling maturity, Construction Innovation, 14(2), pp. 186-209. 
Chen, Y., Dib, H., Cox, R. F., Shaurette, M. and Vorvoreanu, M. (2016). Structural Equation Model of Building Information Modeling Maturity, ASCE J. Constr. Eng. Manage., 142 (9).

Chen, Y., Dib, H., Cox, R. F., Shaurette, M., Vorvoreanu, M., Manoosingh, C. and Maghiar, M. (2016). Global Stakeholders' Perception of Key BIM Maturity Indicators, Osaka, Japan.

Computer Integrated Construction (CIC). (2011). BIM Project Execution Planning Guide, Pennsylvania State University.

Computer Integrated Construction (CIC). (2013). BIM Planning Guide for Facility Owners, The Pennsylvania State University, University Park, PA, USA.

Gerges, M., Ahiakwo, O., Jaeger, M. and Asaad, A. (2016). Building Information Modeling and Its Application in the State of Kuwait, BIM International Journal of Civil, Environmental, Structural, Construction and Architectural Engineering, 10(1), pp. 8186.

Giel, B. and Issa, R. R. A. (2013). Framework for Evaluating the BIM competencies of Building Owners, in 2014 International Conference in Computing in Civil and Building Engineering, Orlando, FL., American Society of Civil Engineers.

Gu, N. and London, K. (2010). Understanding and Facilitating BIM adoption in the AEC industry, Automation in Construction, 19, pp. 988-999.

Gu, N., Singh, V. and London, K. (2014). BIM Ecosystem: The Coevolution of Products, Processes and People, Building Information Modeling: BIM in Current and Future Practice, John Wiley \& Sons, Inc., NJ.

Jensen, P. A. and Johanneson, E. I. (2013). Building Information Modelling in Denmark and Iceland, Engineering Construction and Architectural Management.

Jung, Y. and Joo, M. (2011). Building Information Modeling (BIM) framework for practical implementation, Automation in Construction, 20, pp. 126-133.

Khosrowshahi, F. and Arayici, Y. (2016). Roadmap for implementation of BIM in the UK construction industry, 19, pp. $610-635$.

Mom, M., Tsai, M.-H. and Hsieh, S.-H. (2011). On Decision-Making and TechnologyImplementing Factors for BIM adoption, in International Conference on Construction Applications of Virtual Reality,

Morlhon, R., Pellerin, R. and Bourgault, M. (2014). Building Information Modeling implementation through maturity evaluation and critical success factors management, Elsevier 10.

National Institute of Building Science, N. (2007). United States National Building Information Modeling Standard.

Sacks, R., Koskela, L., Dave, A. B. and Owen, R. (2010). Interaction of Lean and Building Information Modeling in Construction, ASCE J. Constr. Eng. Manage., 136(9), pp. 968980.

Sacks, R. and Pikas, E. (2013). Building Information Modeling Education for Construction Engineering and Management. 1: Industry Requirements, State of the Art, and Gap Analysis, ASCE J. Constr. Eng. Manage.

Succar, B. (2010). Handbook of Research on Building Information Modeling and Construction informatics: Concepts and Technologies, Building Information Modeling Maturity Matrix, Atlanta: Information Science Publishing.

Succar, B., Sher, W. and Williams, A. (2012). Measuring BIM performance: Five Metrics, Architectural Engineering and Design Management, 8, pp. 120 - 142.

Wong, A., Wong, F. K. W. and Nadeem, A. (2010). Attributes of Building Information Modeling implementations in various countries, 6(16). 